Article

\title{
Investigation of Structural and Optoelectronic Properties of Organic Semiconductor Film Based on 8-Hydroxyquinoline Zinc
}

\author{
María Elena Sánchez Vergara ${ }^{1, *} \mathbb{B}$, Lorena Ramírez Vargas ${ }^{1} \mathbb{D}$, Citlalli Rios ${ }^{2}$, Bertha Molina ${ }^{3}$ and \\ Roberto Salcedo $^{2}$ \\ 1 Facultad de Ingeniería, Universidad Anáhuac México, Avenida Universidad Anáhuac 46, \\ Col. Lomas Anáhuac, Estado de México, Huixquilucan 52786, Mexico; lore.rv7199@gmail.com \\ 2 Instituto de Investigaciones en Materiales, Universidad Nacional Autónoma de México, Circuito Exterior s/n, \\ Ciudad Universitaria, Coyoacán 04510, Mexico; citriogo@yahoo.com.mx (C.R.); salcevitch@gmail.com (R.S.) \\ 3 Facultad de Ciencias, Universidad Nacional Autónoma de México, Circuito Exterior s/n, \\ Ciudad Universitaria, Coyoacán 04510, Mexico; mlnbrt@ciencias.unam.mx \\ * Correspondence: elena.sanchez@anahuac.mx
}

check for updates

Citation: Sánchez Vergara, M.E.; Ramírez Vargas, L.; Rios, C.; Molina, B.; Salcedo, R. Investigation of Structural and Optoelectronic

Properties of Organic Semiconductor Film Based on 8-Hydroxyquinoline Zinc. Electronics 2021, 10, 117. https://doi.org/10.3390/electronics 10020117

Received: 5 December 2020

Accepted: 4 January 2021

Published: 8 January 2021

Publisher's Note: MDPI stays neutral with regard to jurisdictional clai$\mathrm{ms}$ in published maps and institutional affiliations.

Copyright: $(\odot 2021$ by the authors. Licensee MDPI, Basel, Switzerland. This article is an open access article distributed under the terms and conditions of the Creative Commons Attribution (CC BY) license (https:// creativecommons.org/licenses/by/ $4.0 /)$.

\begin{abstract}
In this work, we investigated an organic semiconductor based on zinc 8-hydroxyquinoline $\left(\mathrm{ZnQ}_{2}\right)$ and tetracyanoquinodimethane (TCNQ), which can be used as a photoactive layer in organic devices. The semiconductor was optimized by applying density-functional theory (DFT) methods, and four hydrogen bridges were formed between $\mathrm{ZnQ}_{2}$ and $\mathrm{TCNQ}$. Later, thin films of $\mathrm{ZnQ}_{2}$ TCNQ were successfully deposited. The films were structurally and morphologically characterized, and the optical characteristics of the photoactive layer were investigated using ultraviolet-visible spectroscopy and time-dependent density-functional theory (TDDFT) calculations. The comparison and analysis of the experimental and theoretical absorption spectra indicate that the optical bandgap of the photoactive layer is $2.4 \mathrm{eV}$. Additionally, a flexible photo device was manufactured with the active layer $\mathrm{ZnQ}_{2}-\mathrm{TCNQ}$, and its electrical behavior was evaluated under dark and light conditions. The results show a significant change in the behavior of the device when radiation is eliminated; the layer is light sensitive. The electrical resistance in the flexible photo device is associated with the optical behavior of the materials that constitute the active layer.
\end{abstract}

Keywords: DFT calculations; thin film; photoactive layer; optical properties; electrical properties

\section{Introduction}

In recent decades, several studies have been carried out on organic semiconductor devices and their feasible applications [1]. Due to their versatile properties and simple preparation method, organic semiconductors have been used in organic electronics, biological sensors, and renewable energy [1-6]. Organic semiconductors show slow mobility of carriers, although they present $\pi$ delocalized links, a strong chemical interaction between the organic units integrating the semiconductors, and the possibility of generating the molecular blocks that constitute conduction channels [7-9]. The combination of organic semiconductors defines the efficiency of organic devices, like organic solar cells (OSCs) or organic light-emitting diodes (OLEDs), and their performance can be improved by adding interfacial materials between the photoactive layer and the electrodes [5]. This plays a critical role in circumventing the shortcomings of the cathode transport layer (CTL). As a result of the inclusion of interfacial materials, the charge transport is balanced, and the CTL tunes the electrode work function (WF) appropriately [4]. Because of their favorable WF, good electrical conductivity, excellent charge carrier mobility, and good stability under ambient conditions, metal-quinoline (MQ) organic complexes have been used in organic optoelectronic devices [4,7,10-12]. MQ complexes are easily dissolved in polar solvents, making them compatible with solution processing and enhancing their device performances and stability [13]. Due to the above, they have also been studied in analytical 
chemistry as emitters; some examples include $\mathrm{AlQ}_{3}, \mathrm{ZnQ}_{2}$, and $\mathrm{BeQ}_{2}$ [7-19]. It is important to stress that the nature of an attached metal ion affects the stability, evaporability, and emission and color of metal-quinoline derivatives [4,11]. The fluorescence of MQs has resulted in its classification as the most important class of electroluminescent/electron transport materials [20]. Changing the central metal ion affects the luminescence peak position of the metal quinoline $[4,9-11,20]$. In addition, efficiency is inversely proportional to the atomic number of the metal ion, which increases in the intersystem crossing, a phenomenon known as "heavy atom effect" $[4,10,11]$. Due to the above, MQ organic complexes can be used in modern electronics for the development of OLEDs [8-11,20,21].

The first OLEDs with $\mathrm{ZnQ}_{2}$ complexes were reported in 1993 [11], and since then, they have been used to improve electron transport properties due to their $\pi-\pi$ overlap of molecular orbitals. It is thus important to determine whether the $\mathrm{ZnQ}_{2}$ complex can form part of a photoactive layer, enabling it to be used in other types of optoelectronic devices, such as OSCs or photodiodes [22,23]. To verify the above, in the current study, a device constituted by a photoactive layer composed of $\mathrm{ZnQ}_{2}$ and tetracyanoquinodimethane (TCNQ) was manufactured, and its electrical behavior was evaluated. Zinc 8-hydroxyquinoline was used as an electron donor species, whereas TCNQ was used as an electron acceptor. TCNQ is a stable compound and capable of forming stable radicals, with valence electrons located above and below the median plane of the molecule, in delocalized $\pi$ orbitals $[24,25]$. In order to improve the understanding of the structural, vibrational, and absorption properties of the photoactive layer, density-functional theory (DFT) and time-dependent density-functional theory (TDDFT) calculations were performed on the $\mathrm{ZnQ}_{2}$-TCNQ semiconductor. The IR and absorption spectra for the synthesized semiconductor were compared with those obtained theoretically, whereas the experimental optical bandgap was compared with that determined by TDDFT.

\section{Materials and Methods}

8-Hydroxyquinoline zinc $\left(\mathrm{C}_{18} \mathrm{H}_{12} \mathrm{~N}_{2} \mathrm{O}_{2} \mathrm{Zn}\right)$ and 7,7,8,8-tetracyanoquinodimethane $\left(\mathrm{C}_{12} \mathrm{H}_{4} \mathrm{~N}_{4}\right)$ were obtained from Sigma-Aldrich (Saint Louis, MO, USA) and required no further purification. In order to identify their main properties, for example, absorption and vibrational modes of the radicals, FTIR and UV-VIS were determined on a Nicolet iS5 FTIR spectrometer (Thermo Fisher Scientific Inc., Waltham, MA, USA) and a Unicam Spectrophotometer model UV300 (Thermo Fisher Scientific Inc., Waltham, MA, USA), respectively. Afterwards, a $\mathrm{ZnQ}_{2}-\mathrm{TCNQ}$ semiconductor in powder (Figure 1a) was obtained by dissolution of $107.3 \pm 0.1 \mathrm{mg}(0.3 \mathrm{mmol})$ of 8 -hydroxyquinoline zinc and $109.8 \pm 0.1 \mathrm{mg}$ $(0.5 \mathrm{mmol})$ of TCNQ in $20 \pm 1 \mathrm{~mL}$ of methanol. The mixture was kept under reflux at $75^{\circ} \mathrm{C}$ for $24 \mathrm{~h}$, and the obtained solid was filtered and washed with methanol in order to remove "free" amounts of both initial materials. Finally, the mixture was dried in a vacuum for $24 \mathrm{~h}$ at $25^{\circ} \mathrm{C}$ so that the charge transport properties were not influenced by an excess of solvent. For its optical and electrical characterization, the $\mathrm{ZnQ}_{2}-\mathrm{TCNQ}$ semiconductor was deposited as a thin film (see Figure 1b) onto coated glass slides, PET with a transparent film of indium tin oxide (ITO), quartz, and high-resistivity monocrystalline n-type silicon wafers (c-Si). The method for deposition was by sublimation in a high vacuum chamber (Intercovamex, S.A. de C.V., Cuernavaca, Morelos, México) composed of two pumps: a mechanical one that resulted in an initial vacuum of $10^{-3}$ Torr and a turbomolecular one that produced a final vacuum at a chamber of $1 \times 10^{-5}$ Torr. In order to carry out the deposit, the material was heated at $300^{\circ} \mathrm{C}$, the deposition rate was $1.5 \AA / \mathrm{s}$, and thickness was monitored by applying a quartz crystal monitor. It is important to mention that the glass and quartz substrates were previously cut and washed consecutively in an ultrasonic bath with solvents: chloroform, ethanol, and acetone. The silicon substrates, however, were cut and later washed with " $\mathrm{p}$ " solution $\left(10 \mathrm{~mL} \mathrm{HF}, 15 \mathrm{~mL} \mathrm{HNO}_{3}\right.$, and $300 \mathrm{~mL} \mathrm{H}_{2} \mathrm{O}$ ) to remove surface oxide. In order to study the morphology of the films of the charge transfer complex, ZEISS EVO LS 10 scanning electron microscopy (Zeiss International Inc., Göttingen, Germany) was performed for the films deposited on the glass substrates. 
Subsequently, the thin films were analyzed by FTIR spectroscopy in silicon wafers. The optical absorption of the films on the quartz substrates was measured at a wavelength range of 200-1100 nm by UV-VIS spectroscopy. A flexible device (PET/ITO/ZnQ $2-T C N Q / A g)$ was manufactured by sublimation in a high vacuum chamber, and in order to characterize its electrical behavior, a programmable voltage source, a sensitizing station with lighting and temperature controller circuit from Next Robotics (Comercializadora K Mox, S.A. de C.V., CDMX, Mexico), and an autoranging Keithley 4200-SCS-PK1 picoammeter (Tektronix Inc., Beaverton, OR, USA) were employed. The area of the manufactured device was $292 \mathrm{~mm}^{2}$, and the thickness of the $\mathrm{ZnQ}_{2}$-TCNQ active layer was $5.8 \mathrm{~nm}$. The evaluation of electrical behavior in the device was performed both under lighting conditions at different wavelengths and in darkness. External quantum efficiency (EQE) in the device was obtained using a QUESA-1200 system with a LED light source from TFSC Instrument Inc. (Intercovamex, S.A. de C.V., Cuernavaca, Morelos, México) under a white light irradiation of $100 \mathrm{~mW} / \mathrm{cm}$ illumination from an AM1.5 solar simulator.
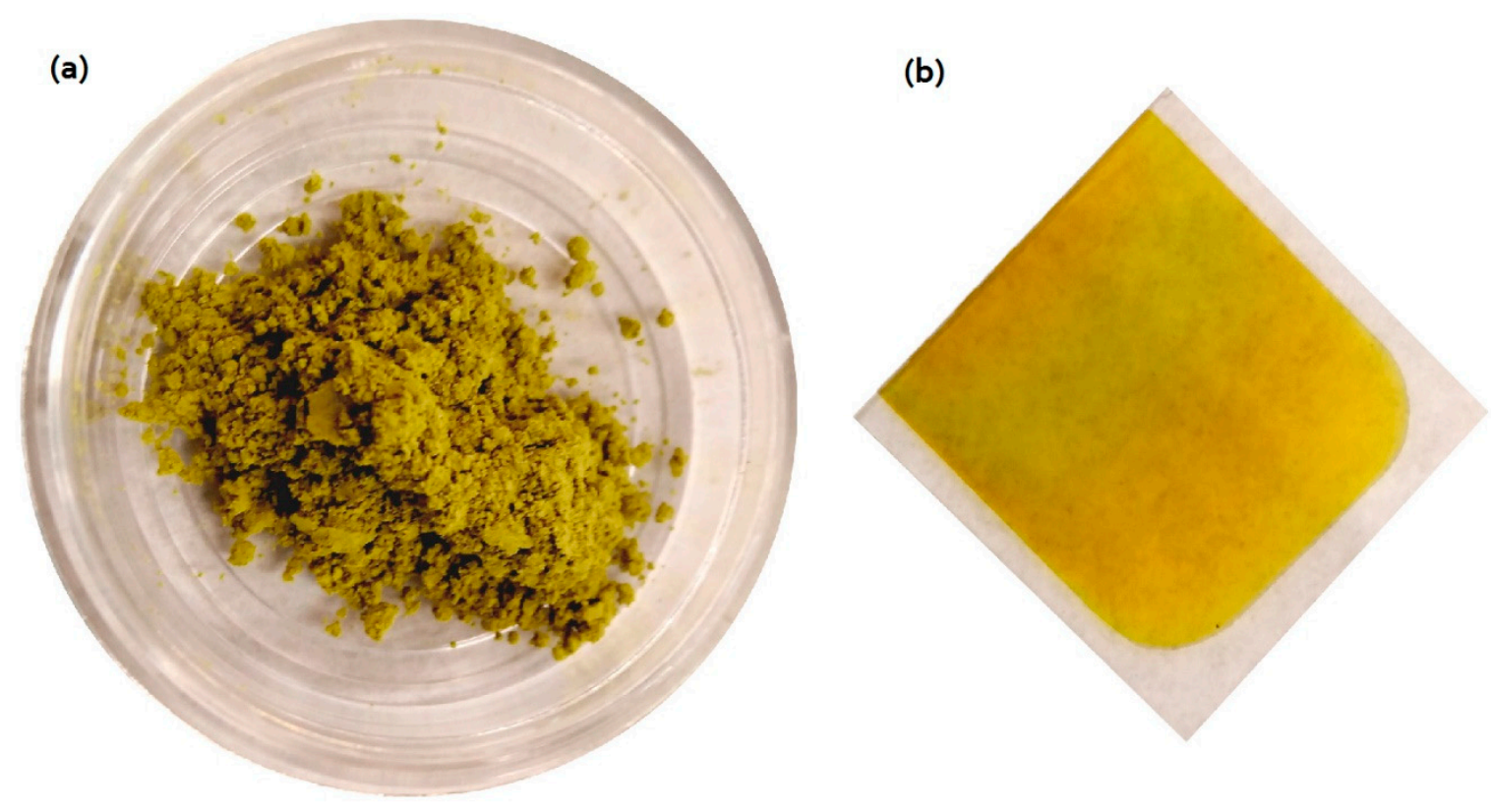

Figure 1. $\mathrm{ZnQ}_{2}$-TCNQ semiconductor in (a) powder and (b) thin film on quartz.

\section{Theoretical Calculations}

For the preliminary structural characterization of the $\mathrm{ZnQ}_{2}-\mathrm{TCNQ}$ compound, we applied a hybrid method based on the combination of Becke's gradient corrections [26] for exchange and Perdew-Wang's for correlation [27]. This is the scheme for the B3PW91 method, which is included in the Gaussian 16 [28] package. The calculations were performed using the $6-31 \mathrm{G}^{* *}$ basis set; it should be said that this method was selected because it has shown good performance in the prediction of structural parameters [29]. Likewise, the Perdew-Burke-Ernzerhof (PBE) [30] generalized gradient approximation (GGA) functional was used for the exchange and correlation terms in the Kohn-Sham Hamiltonian, as implemented in the Amsterdam Density Functional (ADF2013.01) [31] package. This functional was selected because it concurred very well with experimental vibrational and optical parameters for organometallic compounds [32]. The standard Slater-type orbital basis set with a quality of triple- $\zeta$, plus two polarization functions (TZ2P), was used. For the self consistent field (SCF) convergence, an accuracy of $10^{-5}$ Hartree and a gradient of $10^{-4}$ Hartree/Å were selected. In all cases, frequency calculations were carried out at the same level of theory used for the geometrical calculation in order to confirm that the optimized structures were at a minimum on the potential energy surface. The simulated absorption 
spectrum was evaluated for the first 200 singlet-singlet electronic transitions allowed using the PBE/TZ2P method within the TDDFT formulation, as implemented in ADF2013.01.

\section{Results and Discussion}

To determine the feasibility of the experimental synthesis of the charge transfer complex from the donor $\mathrm{ZnQ}_{2}$ and the electronic acceptor TCNQ, the molecular geometry of both precursor compounds and the complex was optimized using the DFT methods described previously. Figure 2a shows the optimized geometry derived from calculations using the B3PW91/6-31G** method $[28,33,34]$. According to our calculations, four hydrogen bridges are formed between $\mathrm{ZnQ}_{2}$ and TCNQ, all of these around $2.5 \AA$ (see Table S1 in Supplementary Materials (SM) for specific N-H and O-H distance values); TCNQ is located under the zone of the hydroxyquinoline that is supported by two oxygen atoms. Interactions between the oxygen and hydrogen atoms are present, as well as between the terminal nitrogen of TCNQ and the hydrogen of hydroxyquinoline. Both DFT methods indicate that the energy value is approximately $17.88 \mathrm{kcal} / \mathrm{mol}$ and corresponds to the whole no-covalent interaction between both parts of the complex. Additionally, in Figure 2b,c, it is apparent that the Highest Ocupied Molecular Orbital (HOMO), which is double degenerated, belongs entirely to $\mathrm{ZnQ}_{2}$, and the Lowest Unoccupied Molecular Orbital (LUMO) corresponds exclusively to TCNQ, revealing the electronic transfer from hydroxyquinoline to TCNQ within this semiconductor. The energy values of the molecular orbitals will enable the correlation of the electronic structure with the functions of the charge transfer complex $\mathrm{ZnQ}_{2}-\mathrm{TCNQ}$ inside the optoelectronic device. For this type of compound, where the charge transport occurs predominantly by means of the HOMO-to-LUMO jump mechanism, energies below $3 \mathrm{eV}$ are required. The above states that an efficient electron injection takes place from the contact electrodes of the device to the semiconductor [34,35]. In this case, the HOMO-LUMO gap predicted using B3PW91 is $1.252 \mathrm{eV}$. Note that this value is below the established limit of $3 \mathrm{eV}$ for the organic semiconductors used in optoelectronic devices. Table 1 summarizes the energy values of the HOMO and LUMO obtained by means of the B3PW91/6-31G** method for the complex $\mathrm{ZnQ}_{2}-\mathrm{TCNQ}$, as well as for its precursor compounds. As apparent in the table, the HOMO and LUMO values for the complex contrast with those obtained for its precursors [36]. This is to be expected when the charge transfer compound is formed; however, it is notable that the predicted values using B3PW91 are near the WF of silver $(\mathrm{WF}=4.2 \mathrm{eV})$ and ITO $(\mathrm{WF}=4.7 \mathrm{eV})$ used later in the manufacture of the device, whose energy diagram is illustrated in Figure 3a. This figure predicts that a device with ohmic contact will be generated, manifesting different phenomena. First, after the electrons are displaced from the HOMO of the donor to the LUMO of the acceptor, they will be injected/extracted towards the cathode. Then, the hollow created in the HOMO will be transferred to the anode without the generation of energy barriers that hinder the charge injection-extraction process.

Table 1. Energy values of orbitals $\mathrm{HOMO}$ and $\mathrm{LUMO}$ for compound $\mathrm{ZnQ}_{2}-\mathrm{TCNQ}$ and their precursor compounds from B3PW91/3-31G**.

\begin{tabular}{ccc}
\hline Compound & HOMO (eV) & LUMO (eV) \\
\hline $\mathrm{ZnQ}_{2}$ & -5.333 & -1.904 \\
$\mathrm{TCNQ}$ & -7.429 & -4.925 \\
$\mathrm{ZnQ}_{2}-\mathrm{TCNQ}$ & -5.605 & -4.353 \\
\hline
\end{tabular}

There are other important factors that influence the transport properties of the compound inside the device, such as the dipole moment of the molecule, which, according to both DFT methods, is $8.81 \mathrm{Db}$. This high polarity indicates the heterogeneous charge distribution along the structure of $\mathrm{ZnQ}_{2}-\mathrm{TCNQ}$ generated by atoms, such as the oxygen of hydroxyquinoline and the nitrogen of TCNQ. In Figure 3b, the electrostatic potential mapped onto the electron density is apparent; the red zones represent the strong electronegative poles, one localized on the heterocyclic region of the hydroxyquinoline moiety and 
some discrete ones on the terminal nitrogen atoms of the TCNQ fragment. The important value of the dipole moment arises from the interaction between these regions, and those that are electropositive are shown in green-blue or blue colors.
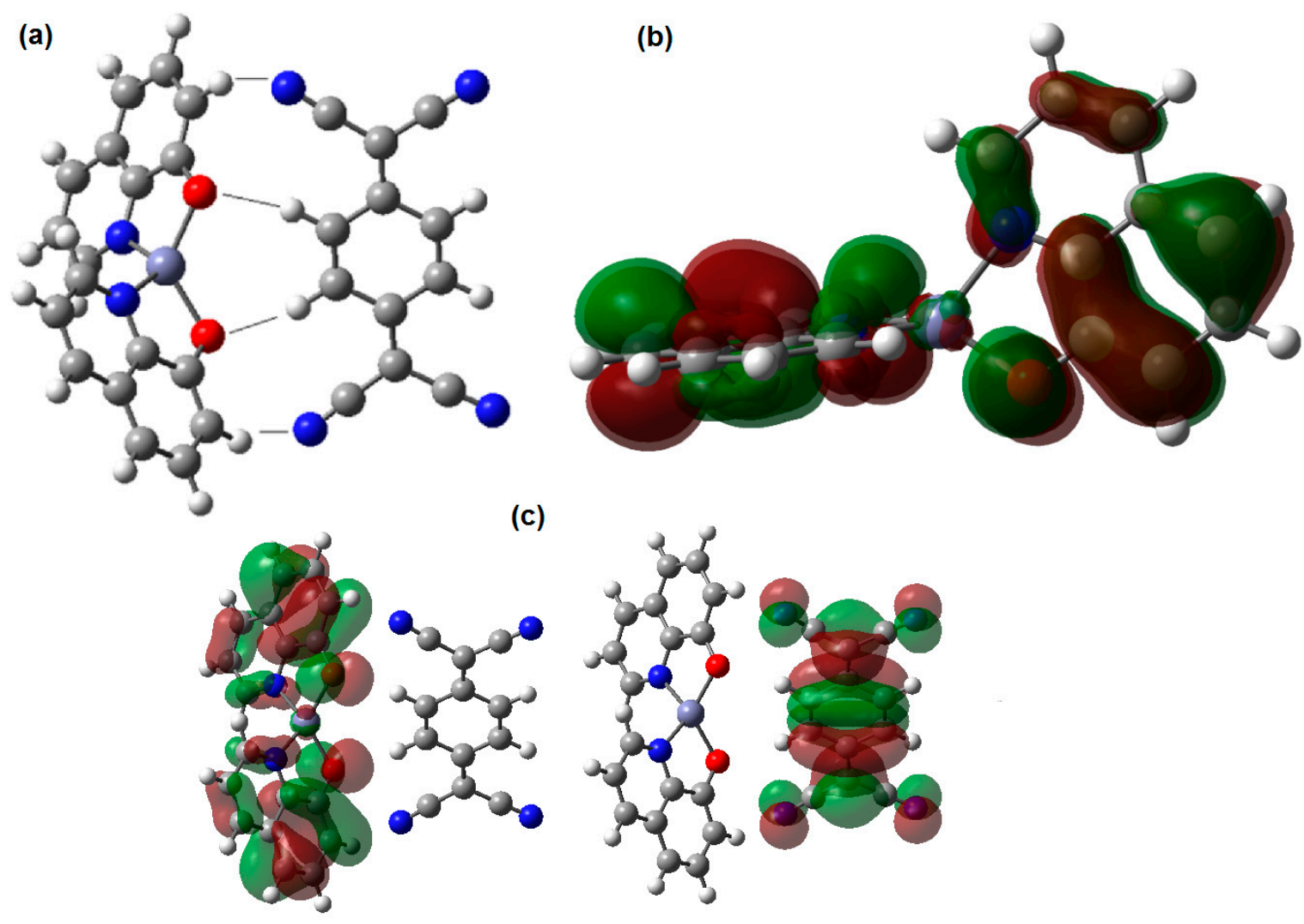

Figure 2. $\mathrm{ZnQ}_{2}-\mathrm{TCNQ}$ (a) optimized structure, (b) orbitals HOMO-LUMO of the formed complex, and (c) separated HOMO and LUMO functions. The last figures were taken from B3PW91/6-31G** calculations.
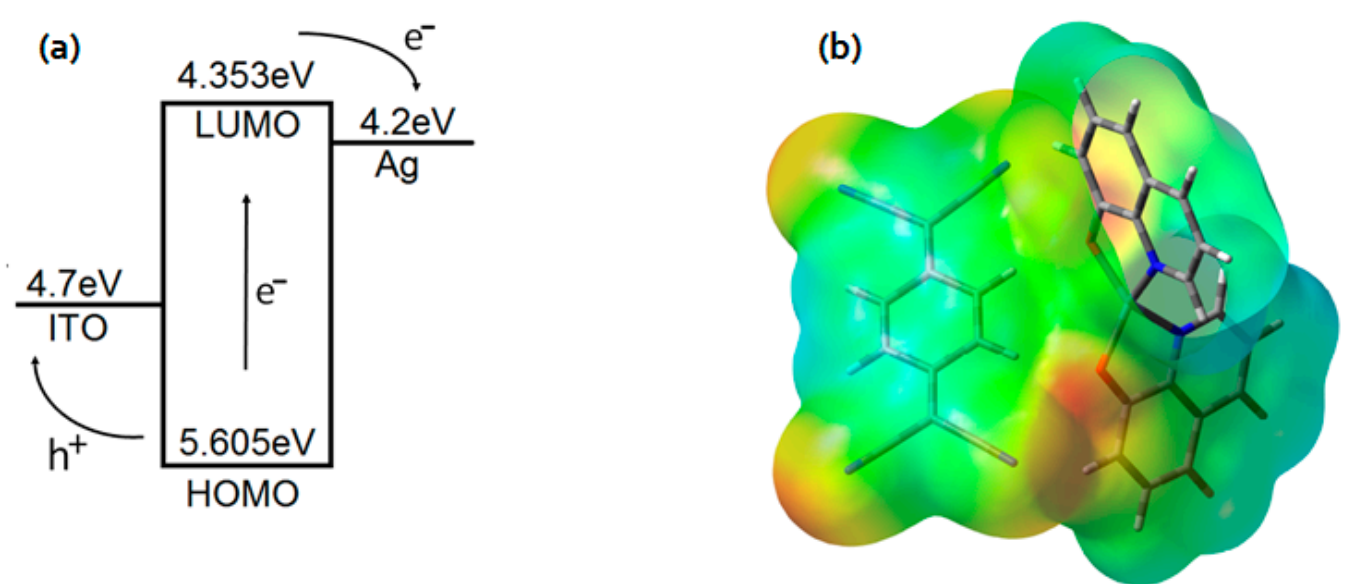

$-5 \times 10^{-3}$

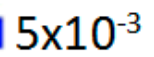

Figure 3. (a) Schematic energy level diagram of the device and (b) electrostatic potential mapped on the electron density for $\mathrm{ZnQ}_{2}$-TCNQ from B3PW91/6-31G** calculations.

The results obtained from B3PW91/6-31G** calculations point to the feasibility of carrying out the experimental synthesis of the semiconductor $\mathrm{ZnQ}_{2}-\mathrm{TCNQ}$. After the synthesis, the semiconductor was characterized in its main functional groups through IR spectroscopy. The IR spectrum was compared with those obtained theoretically, and 
they concur well; both spectra are shown in Figure 4. Notably, the theoretical B3PW91 and PBE spectra are similar, except for small shifts in the bands. Characterizing our experimental spectrum, with reference to our theoretical spectra, we found that the most intense characteristic peaks on the $400-600 \mathrm{~cm}^{-1}$ region can be shown to relate to the asymmetric stretching vibrations of metal ion with attached ligands. In the first zone of the $700-850 \mathrm{~cm}^{-1}$ band, we localized in-plane deformation vibrations of both TCNQ and $\mathrm{ZnQ}_{2}$, whereas the next section in this band is totally dominated by wagging and torsional vibrations in $\mathrm{Q}_{2}$. The band at $1100-1200 \mathrm{~cm}^{-1}$ corresponds to scissors of $\mathrm{H}$ atoms. In the bands in the $1260-1700 \mathrm{~cm}^{-1}$ zone, alternating vibrations were identified in TCNQ or hydroxyquinoline, although in general, the most intense vibrations are associated with the last molecule. The TCNQ signal is observed at $2192 \mathrm{~cm}^{-1}$, which refers to the CN stretching mode of the cyano groups. The main differences between the theoretical and experimental spectra are due to the presence of TCNQ moiety; the corresponding changes are found in the region between $2070 \mathrm{~cm}^{-1}$ and $2380 \mathrm{~cm}^{-1}$. These signals are related to the $\mathrm{C}-\mathrm{H}$ vibrations of TCNQ, which may be in excess. Note that a more detailed analysis is presented in Table 2. It is apparent that, generally, our description concurs well with previous descriptions in the literature [11,37-41]. Thus, the good agreement between the experimental IR spectrum and those obtained theoretically indicates that these calculations constitute an effective approach to this experimental study. Subsequently, the optimized structures in Figure 2 will be used in the subsequent evaluation of the optoelectronic properties of $\mathrm{ZnQ}_{2}-\mathrm{TCNQ}$.

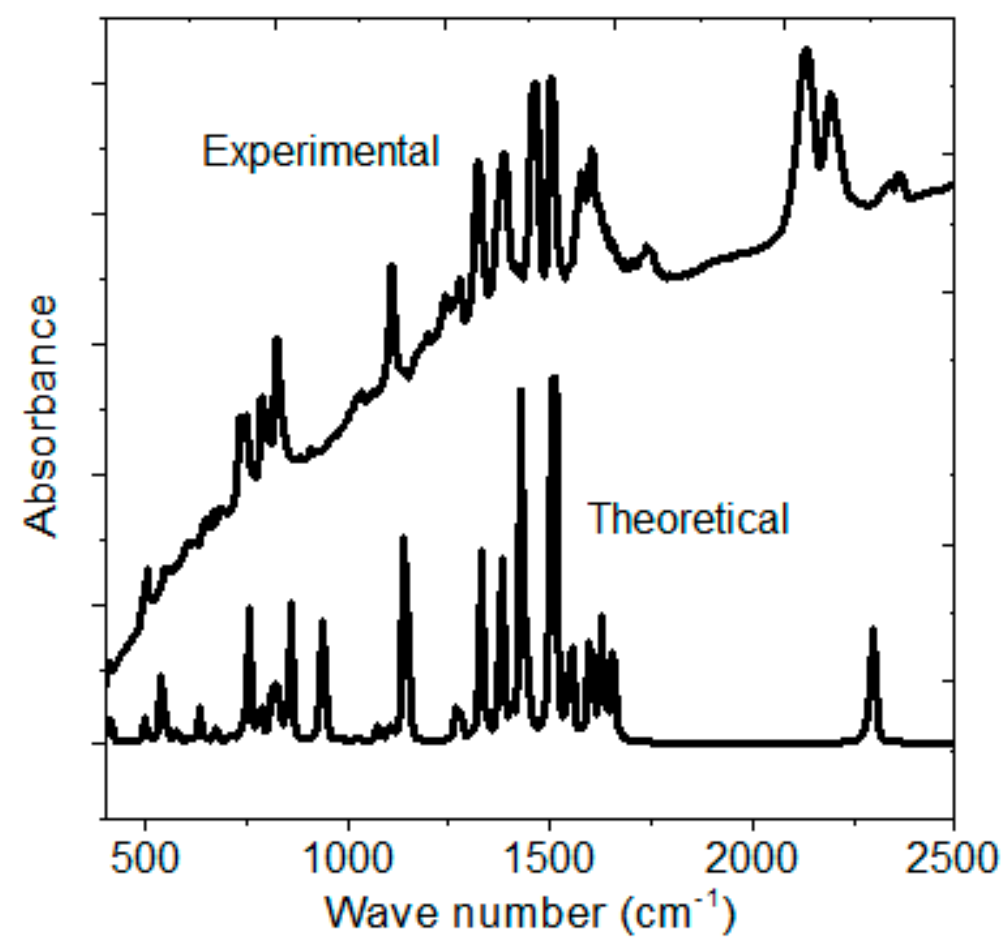

Figure 4. Experimental and calculated IR spectra for $\mathrm{ZnQ}_{2}-\mathrm{TCNQ}$.

In order to evaluate the optical and electrical properties of the organic semiconductor $\mathrm{ZnQ}_{2}-\mathrm{TCNQ}$, we manufactured thin films using the high vacuum evaporation technique. The film over silicon was evaluated by SEM; Figure 5 shows the microphotograph of the film. These images are used to infer homogeneity in the microstructural properties of charge transport in the active region of the device [42]. The image shows a heterogeneous film with irregularly shaped particles distributed throughout the film. The irregular form in films arises as a result of their heterogeneous nucleation and subsequent growth. During the preparation of the films by sublimation in a high vacuum method, the semiconductor is sublimated at $300^{\circ} \mathrm{C}$ and later deposited on the substrates that are at room temperature. 
This thermal shock generates heterogeneous cores that, when grown, give origin to particles with irregular form. According to Figure 5, the bulk heterojunction is formed between hydroxyquinoline and TCNQ. In this type of union, the active layers of optoelectronic devices are formed by a kind of mixture between the electronic donor and the acceptor, which are deposited together. A random distribution of $\mathrm{ZnQ}_{2}$ and TCNQ components is the result, manifesting a greater contact surface and, consequently, a greater diffusion of excitons [43]. Notably, in the manufacture of the described device, an active layer with a bulk heterojunction was chosen rather than a flat heterojunction, because according to the values calculated for the HOMO and LUMO shown in Table 1, the flat heterojunction generates a greater number of energy barriers that limit the transport of electrons and holes in the device.

Table 2. Experimental and calculated IR frequencies and their assignment for $\mathrm{ZnQ}_{2}-\mathrm{TCNQ}$.

\begin{tabular}{|c|c|c|c|}
\hline $\begin{array}{c}\mathrm{ZnQ}_{2}-\mathrm{TCNQ} \\
v\left(\mathrm{~cm}^{-1}\right) \\
\text { Experimental }\end{array}$ & $\begin{array}{c}\mathrm{ZnQ}_{2}-\mathrm{TCNQ} \\
v\left(\mathrm{~cm}^{-1}\right) \\
\text { B3PW91/6-31G }\end{array}$ & $\begin{array}{c}\mathrm{ZnQ2-TCNQ} \\
v\left(\mathrm{~cm}^{-1}\right) \\
\text { PBE/TZ2P }\end{array}$ & Assignment \\
\hline 2192 & 2297 & 2231 & C-N bond stretching in TCNQ \\
\hline 1603 & 1628 & 1609 & $\begin{array}{c}\mathrm{C}=\mathrm{C} \text { bond stretching in the } \\
\text { ring-TCNQ }\end{array}$ \\
\hline 1580 & 1593 & 1582 & $\begin{array}{l}\text { In-plane deformations in the } \\
\text { rings- } Q_{2} \text { by C-N and C-C bond } \\
\text { stretching }\end{array}$ \\
\hline 1462 & 1428 & 1450 & $\begin{array}{c}\text { C-C symmetric bond stretching } \\
\text { in the rings- } Q_{2}\end{array}$ \\
\hline 1175 & 1142 & 1187 & $\begin{array}{c}\text { Asymmetric H scissors in } \\
\text { TCNQ }\end{array}$ \\
\hline $734,648,600$ & $755,635,611$ & $734,644,613$ & $\begin{array}{l}\text { In-plane ring deformations and } \\
\text { wagging vibrations in } Q_{2}\end{array}$ \\
\hline
\end{tabular}

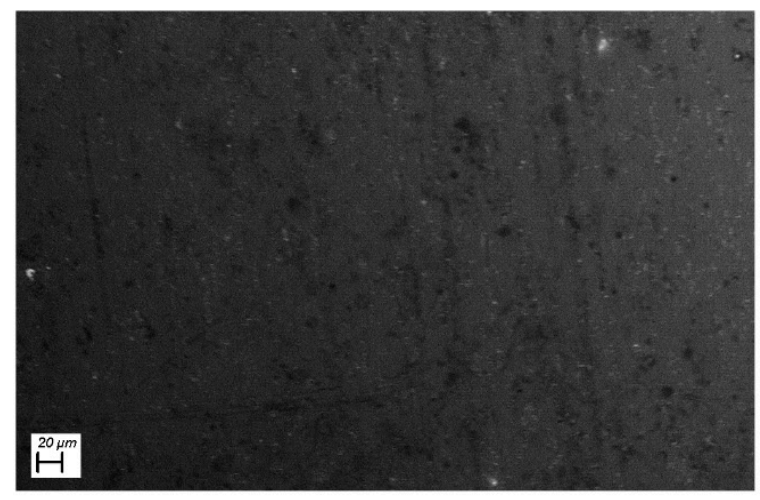

(a)

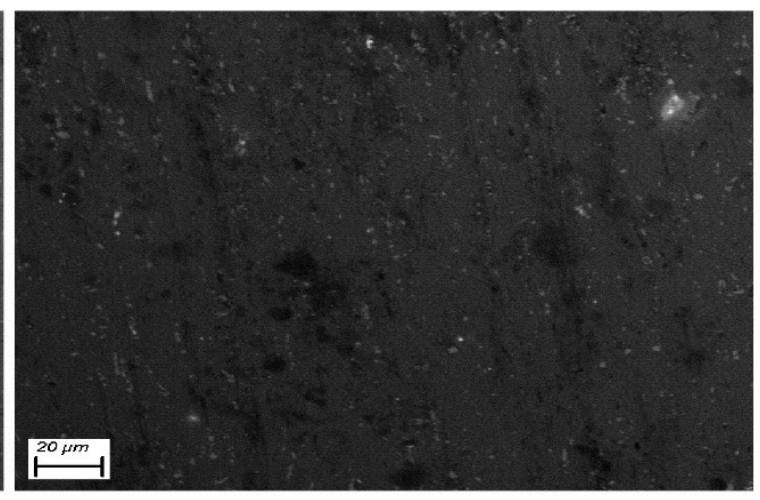

(b)

Figure 5. SEM for $\mathrm{ZnQ}_{2}$-TCNQ film at (a) $500 \times$ and (b) $1000 \times$.

The UV-VIS absorption in the organic semiconductor was evaluated theoretically and experimentally in a thin film over quartz, and the spectra obtained are shown in Figure 6. The $\mathrm{ZnQ}_{2}$-TCNQ film exhibits an ultraviolet absorption peak in the range of 200 $400 \mathrm{~nm}$ (Figure 6a). The absorption spectrum is dominated by intense absorption bands at $198 \mathrm{~nm}, 261 \mathrm{~nm}$, and $367 \mathrm{~nm}$. Theoretically, these bands are located at $211 \mathrm{~nm}, 272 \mathrm{~nm}$, and $340 \mathrm{~nm}$ (see Figure 6b). According to our TDDFT calculations, the band $a$ at 198 and $211 \mathrm{~nm}$ (experimental and theoretical, respectively) mainly consists of five singlet-singlet electronic transitions, the strongest one corresponding to metal-centered charge transfer, the other two mainly related to intramolecular charge transfer in hydroxyquinoline, while the two most energetic ones relate to the electronic interchange between the $\mathrm{ZnQ}_{2}$ and TCNQ species. In Table S2, the parameters characterizing these electronic transitions 
(energy, oscillator strength, molecular electronic transition, and weight of the electronic transition) are presented, and in Figure S1, the molecular orbitals involved in each of these are schematized. Next, the strongest electronic transitions in the absorption band $b$, observed at 261 and $272 \mathrm{~nm}$ (experimental and theoretical, respectively), mainly relate to $\mathrm{HOMO}-1 \rightarrow \mathrm{LUMO}+1, \mathrm{HOMO}-5 \rightarrow \mathrm{LUMO}+2$, and HOMO $-6 \rightarrow \mathrm{LUMO}+1$ transitions, which again represent intramolecular charge transfer in hydroxyquinoline. Interestingly, in this band we also found some less strong electronic transitions that can be assumed to represent metal-to-ligand charge transfer state (i.e., from the zinc ion to the 8HQ molecule (e.g., the electronic transitions at 266.34, 265.43, and $261.95 \mathrm{~nm}$ in Table S2)); we recognize that this type of transition has already been reported [10] and clearly shows $\pi-\pi^{*}$ as it was found in experimental and theoretical fashion [44]. Finally, the lower energy band c, at 367 and $340 \mathrm{~nm}$ (experimental and theoretical, respectively), is characteristic of hydroxyquinoline, as shown in Figure S1, involving singlet-singlet (HOMO, HOMO - 1) $\rightarrow \mathrm{LUMO}+6$ and $(\mathrm{HOMO}, \mathrm{HOMO}-1) \rightarrow \mathrm{LUMO}+5$ transitions, all of which correspond to intramolecular charge transfer in hydroxyquinoline, which concurs well with previous descriptions [45-48]. The differences between the experimental and theoretical spectra are related to the displacement of the three bands in the experimental spectrum with respect to the theoretical one. This differences can be attributed to several factors. First, the experimental values can vary due to the film rugosity, crystallinity, morphology [49], and so forth. Furthermore, the comparison between a single molecule (theoretical result) and a solid state (experimental result) is expected to involve substantial differences.
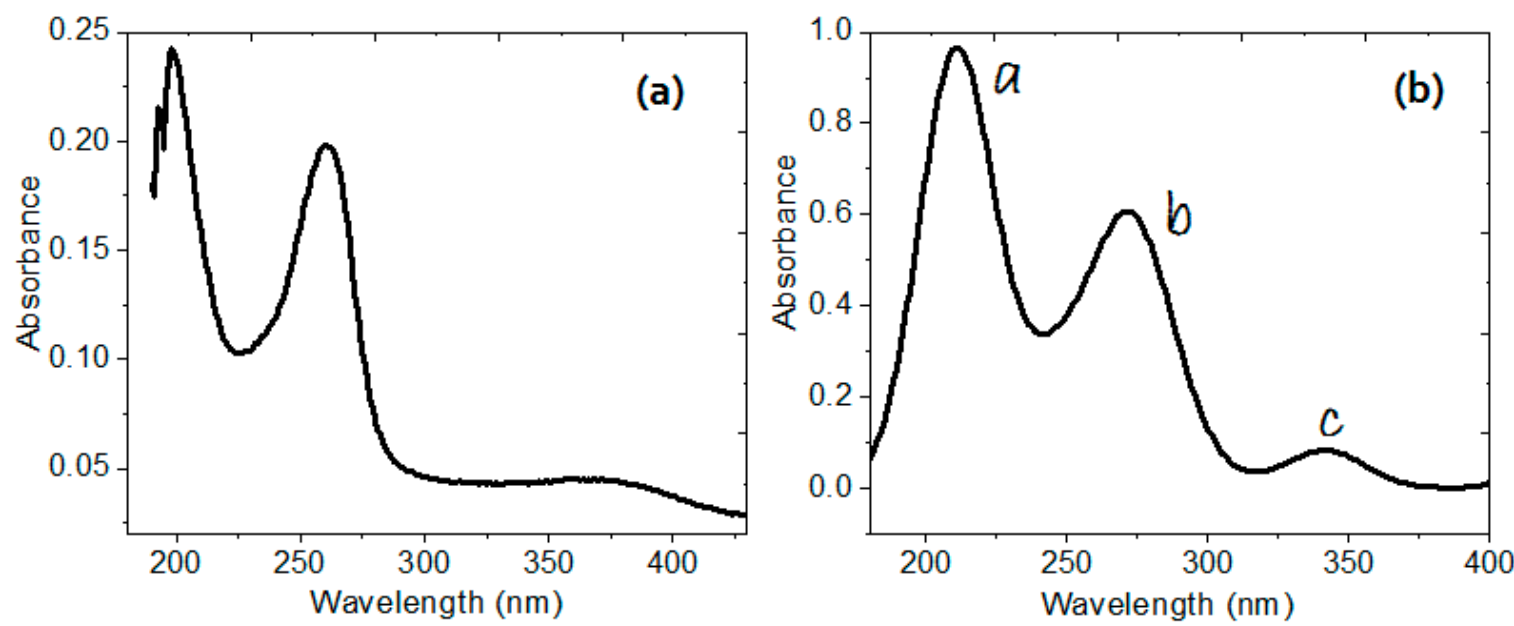

Figure 6. Absorption spectrum of $\mathrm{ZnQ}_{2}$-TCNQ obtained by (a) UV-VIS spectroscopy and (b) simulated absorption spectrum. A Gaussian broadening of $30 \mathrm{~nm}$ was applied.

Information about interband transitions and optical activation energy in our sample was determined with reference to the analysis of the UV-VIS spectral dependence of the absorption near the fundamental absorption edges within the framework of a single electron theory $[12,50]$. The optical activation energy, also known as the optical gap $\left(E_{\text {opt }}\right)$ associated with the semiconductor films, is determined through an extrapolation of the straight-line graphs to zero absorption observed in the spectral dependence of $(\alpha h v)^{1 / 2}$ over a limited range of photon energies ( $h v$ ) (see Figure 7) [51]. The absorption coefficient $(\alpha)$ and frequency $(v)$ are experimentally obtained from the UV-VIS spectrum and the thickness of the film, while $h$ is Planck's constant. The coefficient $\alpha$ near the band edge shows an exponential dependence on photon energy, which usually obeys the Urbach relation $\alpha h v=\beta\left(h v-E_{g}\right)^{n}$, and $\frac{1}{2}$ is a number characterizing the transition process in amorphous semiconductors [51,52]. The optical electronic transitions in the film $\mathrm{ZnQ}_{2}$ TCNQ are of the indirect type, which is characteristic of amorphous films obtained by the high vacuum evaporation process used in this work. When radiation falls on the film, during the UV-VIS spectroscopy, a photon is absorbed by an electron in the HOMO, which 
is localized in $\mathrm{ZnQ}_{2}$ and moves to the LUMO that is found in the TCNQ moiety. During the transition, besides the absorption of a photon, the exchange of a phonon is also produced, changing the electron wave vector [52]. For these indirect transitions, the obtained $E_{\text {opt }}$ is $2.41 \mathrm{eV}$, and considering the energy difference of the HOMO and LUMO orbitals recorded in Table 1, the HOMO-LUMO gap has a value of $1.52 \mathrm{eV}$ and is smaller than $E_{\text {opt }}$. $E_{\text {opt }}$ depends on the structural factors of the material, such as the alternation in bond length, nature of the films, presence of impurities resulting from the doping process, and degree of stacking of the electron donor and acceptor molecules [5]. Conversely, the theoretical bandgap does not consider external effects on the semiconductor molecules, hence the difference in its values with respect to $E_{\text {opt }}$.

In Table 3, the lowest 15 singlet-singlet transitions, apt for comparison with our TDDFT calculations, are presented. Note that there are at least 10 electronic transitions under $2.41 \mathrm{eV}$; however, except for transitions at $2.393 \mathrm{eV}$ and $2.434 \mathrm{eV}$, their oscillator strength $\mathrm{f}$ is at the order of magnitude $10^{-2}$, which is indicative of a weak electronic transition (i.e., although these transitions are feasible, they have a very low probability of occurring). Instead, the order of magnitude of the oscillator strength for the transitions at $2.393 \mathrm{eV}$ and $2.434 \mathrm{eV}$ ( 0.016 and 0.029 u.a., respectively) is the same as for the stronger transitions in band $c$; we can thus suppose that they are likely to have relativity high occurrence. In contrast, the electronic transition at $2.636 \mathrm{eV}$ definitively has to occur, because its oscillator strength is $f=0.4101$ u.a. Note that these three transitions concur very well with the optical gap obtained from our experimental sample. A brief revision shows that the transitions at $2.393 \mathrm{eV}$ and $2.434 \mathrm{eV}$ are both HOMO $-7 \rightarrow \mathrm{LUMO}$ and HOMO $-1 \rightarrow$ $\mathrm{LUMO}+1$ transitions, the first ascribed to a charge transfer from $\mathrm{ZnQ}_{2}$ to TCNQ; however, the strongest at $2.636 \mathrm{eV}$ makes a high intramolecular TCNQ contribution (see Table S3 and Figure S2 in Supplementary Materials). Finally, the theoretical and experimental values obtained indicate the possibility of using thin films of this compound as a photoactive layer in optoelectronic devices (gap $<3 \mathrm{eV}$ ). These results must be complemented with the evaluation of the electrical properties of organic semiconductors.

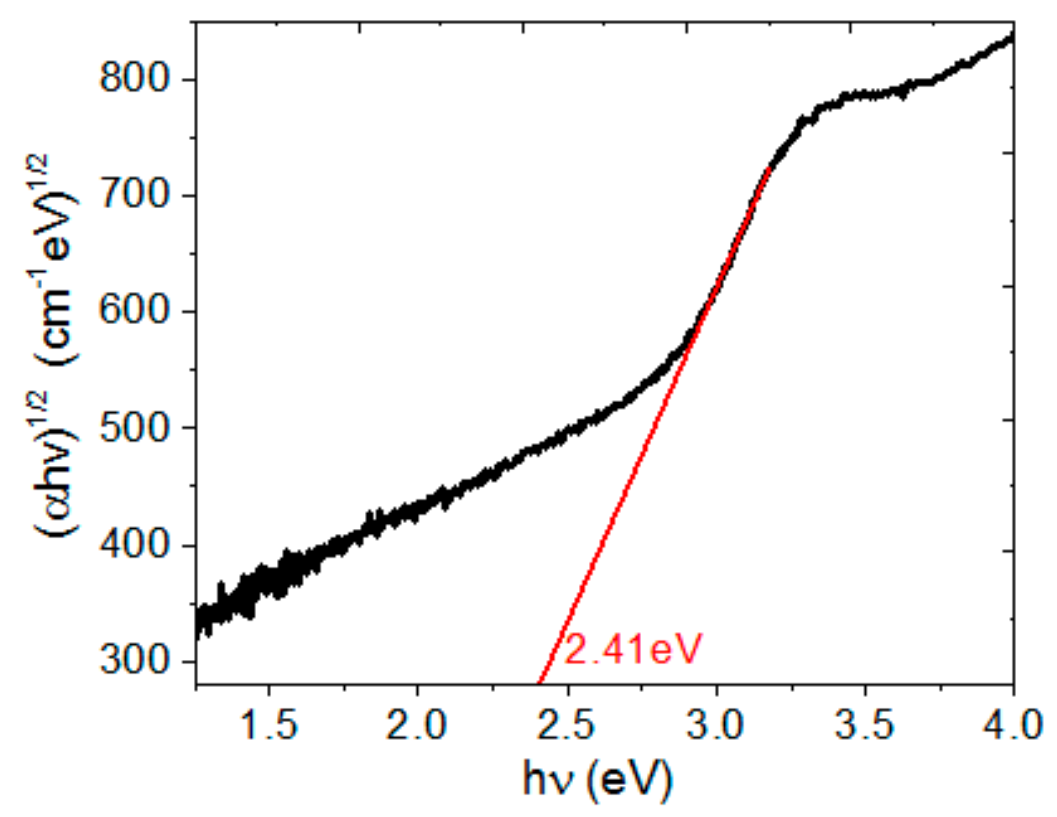

Figure 7. Plot of $(\alpha h v)^{1 / 2}$ as a function of the photon energy $(h v)$ of the $\mathrm{ZnQ}_{2}-\mathrm{TCNQ}$ film. 
Table 3. The first 15 singlet-singlet transitions allowed. $\mathrm{E}_{\mathrm{T}}$ is the energy of the electronic transition, and $\mathrm{f}$ the oscillator strength.

\begin{tabular}{cc}
\hline $\mathbf{E}_{\mathbf{T}}(\mathbf{e V})$ & $\mathbf{F}$ (u.a.) \\
\hline 0.080 & 0.0008 \\
0.098 & 0.0023 \\
1.486 & 0.0016 \\
1.625 & 0.0006 \\
1.662 & 0.0000 \\
1.674 & 0.0011 \\
2.152 & 0.0000 \\
2.153 & 0.0000 \\
2.393 & 0.0161 \\
2.409 & 0.0023 \\
2.434 & 0.0288 \\
2.476 & 0.0078 \\
2.493 & 0.0053 \\
2.636 & 0.4101 \\
2.781 & 0.0000 \\
\hline
\end{tabular}

In order to evaluate the capacity of $\mathrm{ZnQ}_{2}-\mathrm{TCNQ}$ as a photoactive layer, we manufactured a flexible device, $\mathrm{PET} / \mathrm{ITO} / \mathrm{ZnQ}_{2}-\mathrm{TCNQ} / \mathrm{Ag}$ (Figure 8a), that follows the operation described in the energy scheme in Figure 3a. According to the energy scheme, the electron injection barrier between $\mathrm{Ag}$ and $\mathrm{ZnQ}_{2}-\mathrm{TCNQ}$ is $0.153 \mathrm{eV}$, and the hollow injection barrier between $\mathrm{ZnQ}_{2}-\mathrm{TCNQ}$ and ITO is $0.905 \mathrm{eV}$. From the above results, it can be deduced that in the device, the extraction of electrons at the cathode (Ag) will be more efficient than the extraction of holes at the anode (ITO). On the side of the active layer, which is responsible for the absorption of radiation, and where the charge carriers are generated, the characteristics that $\mathrm{ZnQ}_{2}-\mathrm{TCNQ}$ shows and this feature allow for its analysis as a component of optoelectronic devices $[5,43]$. Such characteristics are (i) the layer is formed by an electron donor material and electron acceptor material, which are hydroxyquinoline and TCNQ, respectively; (ii) its components form a kind of homogeneous mixture and can be deposited together, giving place to the dispersed heterojunction, and (iii) it presents a bandgap of less than $3 \mathrm{eV}[5,43]$. Figure $8 \mathrm{~b}$ shows graphs of the current density (J)-voltage (V) obtained under both light and dark conditions. The measurements generate a symmetrical behavior, which indicates the ambipolarity of $\mathrm{ZnQ}_{2}-\mathrm{TCNQ}$ as a photoactive layer. Likewise, irradiating the device results in ohmic behavior with a greater amount of $\mathrm{J}$ transported. This J obeys the law $\mathrm{J} \alpha \mathrm{Vm}$, where " $\mathrm{m}$ " varies with the injection level and is also related to the distribution of trapping centers. Commonly, these traps are not localized at the same energy; they are distributed at different energy levels. As shown in Figure 8b, "m" values were obtained from the slope using a least-square fitting, and J increases linearly, whereas $m>2(m=4)$ shows that the trapping centers are exponentially distributed [12]. It is important to consider that despite the heterogeneous charge distribution obtained from DFT and shown in the electrostatic potential mapped in Figure 3b, no saturation of charges occurs in the device. Saturation would be observed as a change in the slope of the $\mathrm{J}-\mathrm{V}$ curve, and in this case, the device would change to a regime not governed by Ohm's law. Nevertheless, under lighting conditions for this device, there is no excess electrical charge within the active layer for any voltage applied. With respect to the measurement in dark conditions, a significant decrease in $\mathrm{J}$ is observed; this is indicative of high resistance inside the device. For $1 \mathrm{~V}$, the $\mathrm{J}$ carried in lighting conditions is $4.22 \times 10^{-6} \mathrm{~A} / \mathrm{mm}^{2}$, while in dark conditions, it is $1.13 \times 10^{-6} \mathrm{~A} / \mathrm{mm}^{2}$. Because the composition of the active layer and the design of the device were not modified during the time these measurements were taken, it can be assumed that the electrical resistance is associated with the optical behavior of the materials that constitute the active layer. This layer is light sensitive, and apparently, the device behaves like a photodiode $[3,10,21]$. To evaluate the above, J-V measurements were performed on the device with different radiation conditions; the results are presented 
in Figure 8c. In this graph, all the curves reveal ohmic behavior. In the presence of white light, the largest $\mathrm{J}$ is obtained, while the lowest $\mathrm{J}$ is obtained with the green light. This behavior under the green light may relate to the scarce electronic transitions that are possible (see Table 3) with some probability of occurrence at this range of energy $(\sim 2.5-2.25 \mathrm{eV})$. Likewise, according to accepted models in the literature [53], in a photovoltaic device, an electrical current is created from the split the excitons generate when the electron donor species absorb light in such a way that electrons are photoexcited and transferred to the electron acceptor material, leaving behind the so-called "holes" and forming in this manner charge transfer states (excitons) at the interface with the electrons on the acceptor and the holes on the donor [53]. Then, setting in this context of our system, we can say that the transitions are in the range of $2.5 \mathrm{eV}-2.25 \mathrm{eV}$, which do not favor electronic transport, as most of them are intramolecular transitions in either the hydroxyquinoline or TCNQ molecule (see Figure S2 in Supplementary Materials); that is, the electron-hole pair generated is on the donor or acceptor, which very probably favors the process of recombination, canceling the opportunity to create an electrical current. In another context, it is important to consider that the radiation of different wavelengths gives place to a decrement on the transported current density at the same voltage according to the following relationship: $\mathrm{J}($ white $)>\mathrm{J}($ blue $)>\mathrm{J}$ (red) $>\mathrm{J}$ (orange) $>\mathrm{J}$ (violet) $>\mathrm{J}($ yellow $)>\mathrm{J}$ (green). This is probably due to the fact that in the amorphous film of ZnQ2-TCNQ, the transport of charge by hopping occurs by electronic transfers between the energy levels located in the molecules of $\mathrm{ZnQ}_{2}$ and TCNQ that are close to each other. However, the energy of their orbitals is affected by the surrounding environment, which, due to the disorder in the structure of the film, affects each molecule differently and depends on the wavelength of the incident radiation [54]. The device can be used as a light detector, as a variation in the wavelength of the incident radiation in the device generates a change in the current that the device delivers. Additionally, it is important to bear in mind that the values obtained for J, which are reported in Figure 8, are in the same order of magnitude as those reported by Haggag et al. for films of nano Zn(II)-hydroxy-nitrosoquinolate [12] or by Sevgili et al. [3] and Onlaor et al. [7] for aluminum 8-hydroxyquinoline, and that these are superior to those recently reported by Demir et al. for films covered with 8-hydroxyquinoline for diode applications [21]. The above, together with the theoretical and experimental results of UV-VIS spectroscopy and the gap, reaffirm the possibility of using $\mathrm{ZnQ}_{2}-\mathrm{TCNQ}$ as a photoactive layer.

(a)
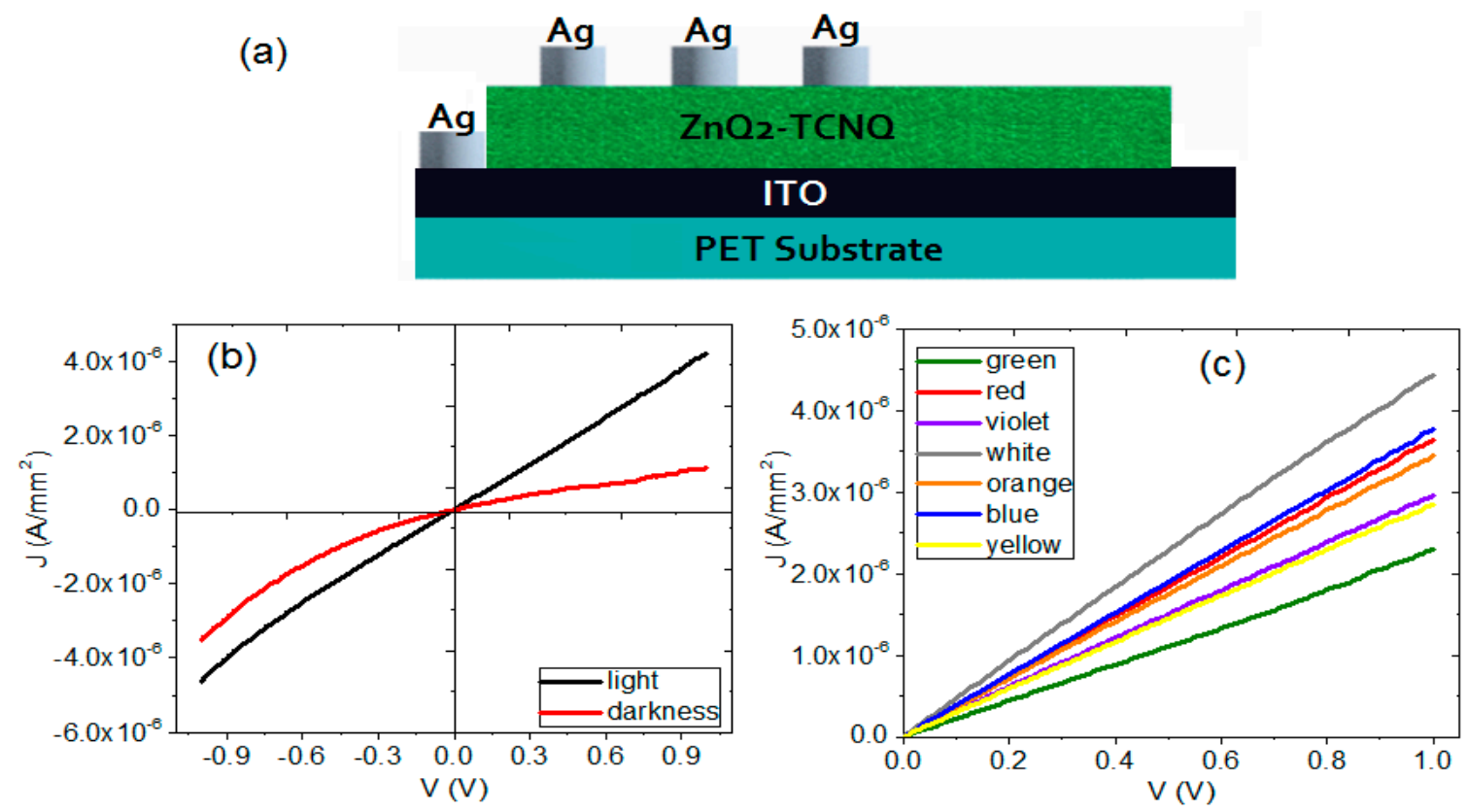

Figure 8. (a) Cross-view image of $\mathrm{Ag} / \mathrm{ZnQ}_{2}-\mathrm{TCNQ} / \mathrm{ITO}$ device. J-V behavior for $\mathrm{ZnQ}_{2}-\mathrm{TCNQ}$ as a photoactive layer (b) under conditions of darkness and light and (c) under different radiation conditions. 
One of the most important parameters used to characterize photodiodes is external quantum efficiency (EQE) [55]. This parameter refers to the number of photons emitted by the device with respect to the number of injected charges. The EQE measured from 375 to $1150 \mathrm{~nm}$ using a LED light source in the device exhibited a maximum value of $1.04 \%$, which, although very low, can be increased. The optimization of the EQE and the enhancement in the functioning of this device may be the subject of future studies. Some of these studies can focus on incorporating an injector, transporting, and blocking layers of both holes and electrons, in addition to the corresponding active layer. The presence of interfacial layers generates a good energy correlation between the energy level of the active layer that participates in the transport of charges and the work function of each electrode. Another aspect that can be improved in the device is the thickness and roughness control of all the films that integrate such device, including the thickness and roughness of the active layer $\mathrm{ZnQ}_{2}$-TCNQ. Talking about this active layer, its amorphous structure can change to a crystalline structure by means of thermal treatments, such as annealing. This treatment has the function of ordering the molecular structure of the semiconductor, favoring the charge transport.

\section{Conclusions}

A photoactive layer constituted by $\mathrm{ZnQ}_{2}$ and TCNQ was manufactured. Hydroxyquinoline was used as an electron donor species, while TCNQ was used as an electron acceptor; this was determined from TDDFT calculations. The experimental and simulated infrared spectra showed that theoretical calculations adequately reproduce the calculated and experimental band positions in the $\mathrm{ZnQ}_{2}-\mathrm{TCNQ}$ compound. A molecular orbital analysis was carried out to define the character of the charge transfer in the organic semiconductor, finding that most of the strongest electronic transitions are an intramolecular charge transfer in $\mathrm{ZnQ}_{2}$, although some metal-centered and metal-to-ligand charge transfers were also identified. Additionally, the experimental optical gap was determined from the analysis of the UV-VIS spectral dependence of the absorption near the fundamental absorption edges. The optical gap for the charge transfer complex corresponds to that of organic semiconductors, with $2.41 \mathrm{eV}$ being the experimental value obtained. From TDDFT calculations, three electronic transitions are predicted at 2.39, 2.43, and $2.63 \mathrm{eV}$. These concur well with the experimental values; the first two manifest a charge transfer contribution from $\mathrm{ZnQ}_{2}$ to TCNQ. However, both transitions are weak compared with that at $2.63 \mathrm{eV}$, which corresponds to an intramolecular charge transfer in TCNQ. From the synthesized compound, a flexible device was manufactured, and its electrical behavior was evaluated under dark and light conditions. Both measurements generated a symmetrical behavior, which indicates the ambipolarity of $\mathrm{ZnQ}_{2}-\mathrm{TCNQ}$ as a photoactive layer and an ohmic dependence between transported $\mathrm{J}$ and $\mathrm{V}$ applied in illuminated conditions. The J carried in light conditions is $4.22 \times 10^{-6} \mathrm{~A} / \mathrm{mm}^{2}$, whereas in dark conditions, it is $1.13 \times 10^{-6} \mathrm{~A} / \mathrm{mm}^{2}$. This layer is light sensitive, and the device behaves as a photodiode.

Supplementary Materials: Supplementary theoretical data. The following are available online at https:/ / www.mdpi.com/2079-9292/10/2/117/s1. Table S1. Distances calculated for the hydrogen bridges formed between $\mathrm{ZnQ}_{2}$ and TCNQ, and HOMO-LUMO gap $\left(\mathrm{E}_{\mathrm{g}}\right)$. Table S2. Molecular electronic transitions calculated for $\mathrm{ZnQ}_{2}$-TCNQ using TDDFT-PBE/TZ2P method, and the parameters characterizing them: energy electronic transition $\left(\mathrm{E}_{\mathrm{T}}\right)$, oscillator strength (f), transition from occupied molecular orbital to unoccupied molecular orbital, and weight of the transition. Table S3. Electronic transitions singlet-singlet with energy comparable to the experimental optical gap $E_{o p t}=2.4 \mathrm{eV}$, and with a higher probability of occurrence. Figure S1. Schematization of the main molecular electronic transitions fashioning the bands in the absorption spectrum. Color code: purple arrows represent the transitions in band (a); blue arrows correspond to transitions in band (b); and light blue arrows represent the transitions in band (c). Figure S2. Schematization of the electronic transitions singlet-singlet with energy comparable to the experimental optical gap $E_{o p t}=2.4 \mathrm{eV}$, and with a higher probability of occurrence (see Table S3). 
Author Contributions: Conceptualization, M.E.S.V. and R.S.; methodology, M.E.S.V., L.R.V., C.R., B.M., and R.S.; software, M.E.S.V., C.R., B.M., and R.S.; validation, M.E.S.V., L.R.V., B.M., and R.S.; formal analysis, M.E.S.V., L.R.V., B.M., and R.S.; investigation, M.E.S.V., L.R.V., C.R., and R.S.; resources, M.E.S.V.; data curation, M.E.S.V., B.M., and R.S.; writing-original draft preparation, M.E.S.V., L.R.V., C.R., and R.S.; writing-review and editing, M.E.S.V., B.M., C.R., and R.S.; visualization, M.E.S.V. and R.S.; supervision, M.E.S.V.; project administration, M.E.S.V.; funding acquisition, M.E.S.V. "Investigation of Structural and Optoelectronic Properties of Organic Semiconductor Film Based on 8-Hydroxyquinoline Zinc." All authors have read and agreed to the published version of the manuscript.

Funding: M.E.S.V. acknowledges the financial support from Anahuac México University, project number NNAIASEVM16070616. B.M. acknowledges the Dirección General de Cómputo y de Tecnologías de la Información (DGTIC-UNAM) for the computer facilities on "Miztli." Project number CAD-UNAM-DGTIC-298.

Conflicts of Interest: The authors declare no conflict of interest.

\section{References}

1. Kayunkid, N.; Tammarugwattana, N.; Mano, K.; Rangkasikorn, A.; Nukeaw, J. Growth and characterizations of tin-doped nickel-phthalocyanine thin film prepared by thermal co-evaporation as novel nanomaterial. Surf. Coat. Technol. 2016, 306, 101-105. [CrossRef]

2. Abuelwafa, A.A.; El-Denglawey, A.; Dongol, M.; El-Nahass, M.M.; Soga, T. Influence of annealing temperature on structural and optical properties of nanocrystalline Platinum octaethylporphyrin (PtOEP) thin films. Opt. Mater. 2015, 49, 271-278. [CrossRef]

3. Sevgili, O.; Canlı, S.; Akman, F.; Orak, I.; Karabulut, A.; Yıldırım, N. Characterization of aluminum 8-hydroxyquinoline microbelts and microdots, and photodiode applications. J. Phys. Chem. Solids 2020, 136, 109128. [CrossRef]

4. Hari, B.; Lyu, C.; Yu, C.; Wen, Z.; Li, F.; Hao, X. Role of Central Metal Ions in 8-Hydroxyquinoline-Doped ZnO Interfacial Layers for Improving the Performance of Polymer Solar Cells. Adv. Mater. Interfaces 2018, 5, 1801172. [CrossRef]

5. Curiel, D.; Más Montoya, M.; Hummert, M.; Riede, M.; Leo, K. Doped-carbazolocarbazoles as hole transporting materials in small molecule solar cells with different architectures. Org. Electron. 2015, 17, 28-32. [CrossRef]

6. Husain, A.A.F.; Hasan, W.Z.W.; Shafie, S.; Hamidon, M.N.; Pandey, S.S. Renewable and Sustainable Energy Reviews. Renew. Sustain. Energy Rev. 2018, 94, 779-791. [CrossRef]

7. Onlaor, K.; Tunhoo, B.; Thiwawong, T.; Nukeaw, J. Electrical bistability of tris-(8-hydroxyquinoline) aluminum (Alq3)/ZnSe organic-inorganic bistable device. Curr. Appl. Phys. 2011, 12, 331-336. [CrossRef]

8. El-Menyawy, E.M. Optical properties of amorphous and crystalline tris(8-hydroxyquinoline) indium films. J. Alloys Compd. 2016, 683, 393-398. [CrossRef]

9. Mohana, J.; Ahila, G.; Bharathi, M.D.; Anbalagan, G. Growth, spectral, optical, thermal, and mechanical behaviour of an organic single crystal: Quinolinium 2-carboxy 6-nitrophthalate monohydrate. J. Cryst. Growth 2016, 450, 181-189. [CrossRef]

10. Shahedi, Z.; Jafari, M.R.; Zolonvari, A.A. Synthesis of $\mathrm{ZnQ}_{2}, \mathrm{CaQ}_{2}$, and $\mathrm{CdQ}_{2}$ for application in OLED: Optical, thermal, and electrical characterizations. J. Mater. Sci. Mater. Electron. 2016, 28, 7313-7319. [CrossRef]

11. Keshmiri, L.; Elahi, S.M.; Jafari, M.R.; Jafari, F.; Parhizgar, S.S. The Blue-Shift of Photoluminescence Spectra of Zinc Complexes of 8-Hydroxyquinoline by Addition of ZnO Nanoparticles. J. Electron. Mater. 2017, 47, 1526-1532. [CrossRef]

12. Haggag, S.M.S.; Farag, A.A.M.; Abdelrafea, M. Spectral, thermal and optical-electrical properties of the layer-by-layer deposited thin film of nano Zn (II)-8-hydroxy-5-nitrosoquinolate complex. Spectrochim. Acta Part A Mol. Biomol. Spectrosc. 2013, 110, 14-19. [CrossRef] [PubMed]

13. Liu, W.; Liang, T.; Chen, Q.; Yu, Z.; Zhang, Y.; Liu, Y.; Fu, W.; Tang, F.; Chen, L.; Chen, H. Solution-processed 8hydroquinolatolithium as effective cathode interlayer for high-performance polymer solar cells. ACS Appl. Mater. Interfaces 2016, 8, 9254-9261. [CrossRef] [PubMed]

14. Sui, Y.L.; Yan, B. Fabrication and photoluminescence of molecular hybrid films based on the complexes of 8-hydroxyquinoline with different metal ions via sol-gel proces. J. Photobiochem. Photobiol. A Chem. 2006, 182, 1-6. [CrossRef]

15. Colle, M.; Brutting, W. Thermal, structural and photophysical properties of the organic semiconductor Alq3. Phys. Status Solidi A 2004, 201, 1095-1115. [CrossRef]

16. Brinkmann, M.; Gadret, G.; Muccini, M.; Taliani, C.; Masciocchi, N.; Sironi, A. Correlation between molecular Packing and optical properties in different crystalline polymorphs and amorphous thin films of mer-tris(8-hydroxyquinoline) aluminum(III). Am. Chem. Soc. 2000, 122, 5147-5157. [CrossRef]

17. Tsuboi, T.; Torii, Y. Selective synthesis of facial and meridional isomers of Alq3. Mol. Cryst. Liq. Cryst. 2010, 529, 42-52. [CrossRef]

18. Kovtun, Y.P.; Prostota, Y.O.; Tolmachev, A.I. Metallochromicmerocyanines of 8-hydroxyquinoline series. Dyes Pigments 2003, 58, 83-91. [CrossRef]

19. Ghedini, M.; La Deda, M.; Aiello, I.; Grisolia, A. Synthesis and photo physical characterization of soluble photo luminescent metal complexes with substituted 8-hydroxyquinolines. Synth. Met. 2003, 138, 189-192. [CrossRef] 
20. Painuly, D.; Masram, D.T.; Rabanal, M.E.; Nagpure, I.M. The effect of ethanol on structural, morphological and optical properties of Li(I) 8-hydroxyquinoline phosphor. J. Lumin. 2017, 192, 1180-1190. [CrossRef]

21. Demir, R.; Kaya, İ. Comparison of electrical characteristics of zinc oxide and cadmium sulfide films covered with 8hydroxyquinoline for diode applications. J. Mater. Sci. Mater. Electron. 2019, 30, 7103-7109. [CrossRef]

22. Kao, P.; Chu, S.; Huang, H.; Tseng, Z.; Chen, Y. Improved efficiency of organic photovoltaic cells using tris (8-hydroxy-quinoline) aluminum as a doping material. Thin Solid Films 2009, 517, 5301-5304. [CrossRef]

23. Krishnakumar, V.; Nagalakshmi, R.; Janaki, P. Growth and spectroscopic characterization of a new organic nonlinear optical crystal-8-hydroxyquinoline. Spectrochim. Acta Part A 2005, 61, 1097-1103. [CrossRef] [PubMed]

24. Gucciardi, P.G.; Trusso, S.; Vasi, C.; Patanè, S.; Allegrini, M. Nano-Raman imaging of Cu-TCNQ clusters in TCNQ thin films by scanning near-field optical microscopy. Phys. Chem. Chem. Phys. 2002, 4, 2747-2753. [CrossRef]

25. Bendikov, M.; Wudl, F.; Perepichka, D.F. Tetrathiafulvalenes, oligoacenenes, and their buckministerfullerene derivatives: The brick and mortar of organic electronics. Chem. Rev. 2004, 104, 4891-4945. [CrossRef] [PubMed]

26. Beck, A.D. Density-functional exchange-energy approximation with correct asymptotic behavior. Phys. Rev. A 1988, 38, 3098-3100. [CrossRef] [PubMed]

27. Perdew, J.P.; Wang, Y. Accurate and simple analytic representation of the electron-gas correlation energy. Phys. Rev. B 1992, 45, 13244-13249. [CrossRef]

28. Frisch, M.J.; Trucks, G.W.; Schlegel, H.B.; Scuseria, G.E.; Robb, M.A.; Cheeseman, J.R.; Scalmani, G.; Barone, V.; Petersson, G.A.; Nakatsuji, H.; et al. Gaussian16, Revision A.03; Gaussian Inc.: Wallingford, CT, USA, 2017.

29. Crowley, J.M.; Tahir-Kheli, J.; Goddard, W.A., III. Resolution of the band gap prediction problem for material design. J. Phys. Chem. Lett. 2016, 7, 1198-1203. [CrossRef]

30. Perdew, J.P.; Burke, K.; Ernzerhof, M. Generalized gradient approximation made simple. Phys. Rev. Lett. 1996, 77, 3865. [CrossRef]

31. ADF2013.01 SCM. Theoretical Chemistry; Vrije Universiteit: Amsterdam, The Netherlands; Available online: https://www.scm. $\mathrm{com} /$ (accessed on 30 November 2020).

32. Santiago, P.F.; Mercado, J.R.S.; Brito, B.M. DFT/TD-DFT studies on electronic and photophysical properties of Auranofin: A reference $\mathrm{Au}(\mathrm{I})$ complex. Polyhedron 2020, 180, 114262. [CrossRef]

33. Ari, H.; Büyükmumcu, Z. Comparison of DFT functionals for prediction of ban gap for conjugated polymers and effect of HF Exchange term percentage and basis set on the performance. Comput. Mater. Sci. 2017, 138, 70-76. [CrossRef]

34. Newman, C.R.; Frisbie, C.D.; Filho, D.A.S.; Bredas, J.L.; Ewbank, P.C.; Mann, K.R. Introduction to Organic Thin Film Transistors and Design of n-Channel Organic Semiconductors. Chem. Mater. 2004, 16, 4436-4451. [CrossRef]

35. Hutchison, G.; Ratner, M.; Marks, T. Hopping transport in conductive heterocyclic oligomers: Reorganization energies and substituent effects. J. Am. Chem. Soc. 2005, 127, 2339-2350. [CrossRef]

36. Rainbolt, J.E.; Padmaperuma, A.B.; Govind, N.; Gaspar, D.J. Substituent effects on the geometric and electronic properties of tetracyano-p-quinodimethano (TCNQ): A theoretical study. Mol. Simul. 2013, 39, 350-356. [CrossRef]

37. Phillips, J.P.; Deye, J.F. Infrared spectra of oxine chelates. Anal. Chim. Acta 1957, 17, 231-233. [CrossRef]

38. Gavrilko, T.; Fedorovich, R.; Dovbeshko, G.; Marchenko, A.; Naumovets, A.; Nechytaylo, V.; Puchkovska, G.; Viduta, L.; Baran, J.; Ratajczak, H. FTIR spectroscopic and STM studies of vacuum deposited aluminium (III) 8-hydroxyquinoline thin films. J. Mol. Struct. 2004, 704, 163-168. [CrossRef]

39. Tackett, J.E.; Sawyer, D.T. Properties and infrared spectra in the potassium bromide region of 8-quinolinol and its metal chelates. Inorg. Chem. 1964, 3, 692-696. [CrossRef]

40. Engelter, C.; Jackson, G.E.; Knight, C.L.; Thornton, D.A.J. Spectra-structure correlations from the infrared spectra of some transition metal complexes of 8-hydroxyquinoline. J. Mol. Struct. 1983, 213, 133-144. [CrossRef]

41. Pfeiffer, M.; Fritz, T.; Blochwitz, J.; Nollau, A.; Plönnigs, B.; Beyer, A.; Leo, K. Controlled Doping of Molecular Organic Layers: Physics and Device Prospects. Adv. Solid State Phys. 1999, 39, 77-90. [CrossRef]

42. Kim, P.; Zhang, X.H.; Domercq, B.; Jones, S.C.; Hotchkiss, P.J.; Marder, S.R.; Kippelen, B.; Perry, J.W. Solution-processible high-permittivity nanocomposite gate insulators for organic field-effect transistors. Appl. Phys. Lett. 2008, 93, 243. [CrossRef]

43. Heeger, A.J. Bulk Heterojunction Solar Cells: Understanding the Mechanism of Operation. Adv. Mater. 2014, 26, 10-28. [CrossRef] [PubMed]

44. Gutiérrez-González, I.; Molina-Brito, B.; Götz, A.W.; Castillo-Alvarado, F.L.; Rodríguez, J.I. Structural and electronic properties of the P3HT-PCBM dimer: A theoretical study. Chem. Phys. Lett. 2014, 612, 234-239. [CrossRef]

45. González, S.R.; Casado, J.; López Navarrete, J.T.; Blanco, R.; Segura, J.L. A $\beta$-naphthaleneimide-modified terthiophene exhibiting charge transfer and polarization through the short molecular axis. Joint spectroscopic and theoretical study. J. Phys. Chem. A 2008, 112, 6732-6740. [CrossRef] [PubMed]

46. Blanco, R.; Gómez, R.; Seoane, C.; Segura, J.L.; Mena-Osteritz, E.; Bäuerle, P. An ambipolar peryleneamidine monoimide-fused polythiophene with narrow band gap. Org. Lett. 2007, 9, 2171-2174. [CrossRef]

47. Hoshi, T.O.; Kumagai, K.; Inoue, K.; Enomoto, S.; Nobe, Y.; Kobayashi, M. Electronic absorption and emission spectra of Alq3 in solution with special attention to a delayed fluorescence. J. Lumin. 2008, 128, 1353-1358. [CrossRef]

48. Kalinowski, J.; Fattori, V.; Di Marco, P. Surface reactions of singlet excitons in solid films of 8-hydroxyquinoline aluminium (Alq3). Chem. Phys. 2001, 266, 85-96. [CrossRef] 
49. Örek, C.; Arslan, F.; Gündüz, B.; Kaygili, O.; Bulut, N. Comparison of experimental photonic and refractive index characteristics of the TBADN films with their theoretical counterparts. Chem. Phys. Lett. 2018, 696, 12-18. [CrossRef]

50. Farag, A.A.M.; Yahia, I.S. Structural, absorption and optical dispersion characteristics of rhodamine B thin films prepared by drop casting technique. Opt. Commun. 2010, 283, 4310-4317. [CrossRef]

51. Tauc, J. Optical properties and electronic structure of amorphous Ge and Si. J. Mater. Res. Bull. 1968, 3, 37-46. [CrossRef]

52. El-Nahass, M.M.; Sallam, M.M.; Alí, H.A.M. Optical properties of thermally evaporated metalfree phathalocyanine $\left(\mathrm{H}_{2} \mathrm{Pc}_{\mathrm{c}}\right)$ thin films. Int. J. Mod. Phys. B 2005, 19, 4057-4071. [CrossRef]

53. Servaites, J.D.; Ratner, M.A.; Marks, T.J. Organic solar cells: A new look at traditional models. Energy Environ. Sci. 2011, 4, 4410-4422. [CrossRef]

54. Bässler, H.; Köler, A. Unimolecular and Supramoleculr Electronics I, Chemistry and Physics Meet at Metal Molecule Interfaces; Metzger, R.M., Ed.; Springer: Berlin/Heidelberg, Germany, 2012; Volume 312.

55. Tsutsui, T.; Aminaka, E.; Lin, C.P.; Kim, D.-U. Extended molecular design concept of molecular materials for electroluminescence: Sublimed-dye films, molecularly doped polymers and polymers with chromophores. Phil. Trans. R. Soc. Lond. A 1997, 355, 801-814. [CrossRef] 